\title{
Actividad antifúngica y antibacteriana in vitro del extracto etanólico de Usnea laevis frente a Candida albicans, Staphylococcus aureus y Pseudomonas aeruginosa
}

In-vitro antifungal and antibacterial activity of the ethanolic extract of Usnea laevis against Candida albicans, Staphylococcus aureus and Pseudomonas aeruginosa

\author{
Cristhina Estefanía Jaramillo-Ordoñez ${ }^{1, a}$
}

\section{RESUMEN}

Los líquenes son asociaciones simbióticas mutualistas que se dan entre un hongo y organismos fotoautótrofos tales como algas o cianobacterias. Presentan altas concentraciones de sustancias liquénicas, las cuales son químicamente complejas y han presentado una marcada actividad antifúngica y antibacteriana. Objetivo: Evaluar la actividad antifúngica y antibacteriana (in vitro) del extracto etanólico de Usnea laevis frente a Candida albicans, Staphylococcus aureus y Pseudomonas aeruginosa. Material y métodos: Las sustancias liquénicas presentes en Usnea laevis fueron extraídas mediante el método de Soxhlet y fueron analizadas químicamente por cromatografía acoplado a espectrometría de masas. Para la evaluación de la actividad antifúngica y antibacteriana se utilizó la técnica de Kirby-Bauer. Resultados: Dentro de la composición química del extracto liquénico se tuvo ácido úsnico, eugenol, ergosterol entre otros. Para una concentración de $27 \mathrm{mg} / \mathrm{ml}$ del extracto etanólico de Usnea laevis, Staphylococcus aureus fue encontrado sensible siendo esta concentración la que mejores resultados de inhibición arrojó; mientras que la concentración de $11 \mathrm{mg} / \mathrm{ml}$ no fue efectiva frente a las cepas evaluadas. Conclusiones: El extracto etanólico de Usnea laevis posee propiedades antifúngicas y antibacterianas frente a Candida albicans, Pseudomonas aeruginosa y Staphylococcus aureus.

PALABRAS CLAVE: Usnea, antifúngicos, antibacterianos, extractos vegetales. (Fuente: DeCS BIREME).

\section{SUMMARY}

Lichens are symbiotic associations between fungi and seaweed or cyanobacteria. Objective: to evaluate the in-vitro antifungal and antibacterial activity of the ethanolic extract of Usnea laevis against Candida albicans, Staphylococcus aureus and Pseudomonas aeruginosa. Methods: lichened substances present in Usnea laevis were extracted using the Soxhlet methods and were analyzed by chromatography coupled to mass spectrometry. The Kirby-Bauer method was used to evaluate both the antibacterial and antifungal activity. Results: Usnic acid, eugenol, and ergosterol were the compounds found. S. aureus was sensitive at a concentration of $27 \mathrm{mg} / \mathrm{ml}$ of the enolic extract, the $11 \mathrm{mg} / \mathrm{ml}$ concentration was not effective. Conclusions: The ethanolic extract of Usnea laevis has antibacterial and antifungal properties against the pathogens tested.

KEYWORDS: Usnea, antifungal agents, anti-bacterial agents, plant extracts. (Source: MeSH NLM). INTRODUCCIÓN

Los líquenes son asociaciones simbióticas mutualistas que se dan entre un hongo (micobionte) y organismos

1 Facultad de Ciencias Biológicas y Ambientales, Universidad Central del Ecuador. Quito, Ecuador.

a Bióloga. 
fotoautótrofos tales como algas o cianobacterias (fotobiontes); en donde el micobionte se encuentra dominando esta asociación (1), esta relación da lugar a la producción de metabolitos primarios y secundarios los cuales son químicamente complejos; y distintos, en su mayoría, a los que se generan en las plantas $(2,3)$.

Estos compuesto ejercen una amplia variedad de acciones biológicas antivirales, antiinflamatorios, analgésicos, antipiréticos, antiproliferativos, efectos leshmanicidas y citotóxicos involucrando cambios en la permeabilidad de la membrana causando lisis celular $(4,5)$.

Se incluye la actividad antimicrobiana y antifúngica frente a bacterias Gram positivas y negativas, micobacterias y hongos levaduriformes (6), reportando su efecto mediante la obtención del extractos acuosos metanólicos y etanólicos de diversas especies tales como Usnea campestris y Usnea densirostra frente a Staphylococcus aureus, Bacillus subtilis, Micrococcus luteus (7), así como también la actividad inhibitoria de los extractos metanólico y acetónico de Usnea ghattensis frente a Staphylococcus aureus, Bacillus subtilis, Bacillus licheniformis y Bacillus megaterium (8).

Con respecto Usnea leavis, un estudio reportó su potencial antifúngico frente a hongos fitopatógenos, pero no se han reportado investigaciones en esta especie sobre su efecto antimicrobiano y antifúngico en cepas de importancia médica (9).

A esto se suma el hecho que en la actualidad la resistencia de microorganismos patógenos es alarmante, siendo cada vez más frecuente y contribuyen de manera significativa a la carga producida por enfermedades febriles del tracto reproductivo, respiratorio y diarreicas, haciendo que el tratamiento sea mucho más difícil de abordar por el deterioro de la efectividad y eficacia de los fármacos, haciendo que se vuelvan obsoletos los tratamientos para dichas infecciones y que cada vez se disponga de menos opciones terapéuticas (10).

En la búsqueda de nuevas opciones para el control y tratamiento de este tipo de enfermedades; tanto plantas, hongos y líquenes son importantes para la investigación farmacológica sirviendo como base para la síntesis de nuevos medicamentos o compuestos farmacológicamente activos, por lo tanto es importante el estudio la actividad antifúngica y antibacteriana que presentan los extractos liquénicos ya que podrían dar como resultado nuevas alternativas para el control de estos organismos patógenos.

El objetivo de la investigación fue determinar la composición química del extracto etanólico de Usnea laevis y evaluar la actividad antifúngica y antibacteriana del mismo, frente a Candida albicans, Staphylococcus aureus y Pseudomonas aeruginosa.

\section{MATERIAL Y MÉTODOS}

Estudio descriptivo, observacional y transversal. La población microbiana estuvo representada por las cepas de Candida albicans ATCC $® 10231^{\mathrm{TM}}$, Pseudomonas aeruginosa ATCC ${ }^{\circledR} 9027^{\mathrm{TM}}$ y Staphylococcus aureus ATCC ${ }^{\circledR} 25923^{\mathrm{TM}}$ obtenidas en una casa comercial; se trabajó con cuatro tratamientos y cuatro repeticiones por cepa, cada ensayo se hizo por triplicado teniendo un total de 144 unidades experimentales.

El talo liquénico de Usnea laevis se lo obtuvo en el Mercado Santa Clara ubicado en el Cantón Quito, Provincia de Pichincha, proveniente del Cerro Atacazo (Quito-Pichincha) según información dada por parte de los comerciantes; la identificación y caracterización macroscópica y microscópica se realizó en el Laboratorio de Micología Aplicada de la Universidad Central del Ecuador, utilizando claves taxonómicas y la asesoría de especialistas. Para corroborar la identificación se contrasto la muestra liquénica con las existentes en el Herbario QCAZ de la Pontifica Universidad Católica del Ecuador.

Para la obtención del extracto se molió y tamizó 20,92 g de talo liquénico, y se lo extrajo mediante el método de Soxhelt con etanol al $96 \%$, a una temperatura de $78,4^{\circ} \mathrm{C}$ durante 90 minutos aproximadamente.

Se tuvo una concentración inicial de $27,5 \mathrm{mg} /$ $\mathrm{ml}$ y a partir de esta se prepararon concentraciones de $22,5 \mathrm{mg} / \mathrm{ml}, 16,5 \mathrm{mg} / \mathrm{ml}$ y $11 \mathrm{mg} / \mathrm{ml}$ (11-13). La composición química se determinó mediante un cromatógrafo de gases Agilent $7890^{\mathrm{a}}$ año 2010 acoplado a un espectrómetro de masas MSD 5975 año 2008 .

Pseudomonas aeruginosa fue activada a partir de viales de CRYOBANK en $50 \mathrm{ml}$ de medio liquido BHI- BD Difco $^{\mathrm{TM}}$ (infusión cerebro corazón) para ser sembrada por estriado en agar MacConkey (BD Difco ${ }^{\mathrm{TM}}$ ) (14), Staphylococcus aureus y Candida albicans fueron activadas a partir de una unidad de KWIKSTIK para ser sembradas en 
Manitol (BD Difco $\left.{ }^{\mathrm{TM}}\right)$ y Sabouraud (BD Difco ${ }^{\mathrm{TM}}$ ) respectivamente (6).

La actividad antifúngica y antibacteriana del extracto etanólico fue evaluada mediante la técnica de Kirby-Bauer empleando como medio de cultivo TSABD Difco ${ }^{\mathrm{TM}}$ (Tripticasa Soya agar) para las cepas bacterianas y agar Sabouraud para la cepa levaduriforme, cuya turbidez del inoculo fue previamente ajustada a una escala de $0,5 \mathrm{McFarland}\left(1 \times 10^{8} \mathrm{ufc} / \mathrm{ml}\right)$ utilizando como referencia de turbidez un tubo de ensayo con $0,05 \mathrm{ml}$ de $\mathrm{BaCl} 2$ al 1\% y $9,95 \mathrm{ml}$ de ácido clorhídrico $(\mathrm{HCl})$ al $1 \%(6)$.

Para la siembra del microorganismo, se sumergió un hisopo de algodón estéril en la suspensión ajustada y se inoculó en la placa con agar Mueller-Hinton procurando que la caja se encuentre totalmente humedecida con la suspensión.

Se colocaron discos de sensibilidad en blanco (OXOID) en la caja petri y se inoculó $10 \mu \mathrm{l}$ de las diferentes concentraciones del extracto con la ayuda de una micropipeta (Eppendorf). Se utilizó como control negativo etanol al $96 \%$ remojando a los discos en blanco y dejándolos reposar por un lapso de 10 minutos antes de ser utilizados y como control positivo gentamicina de $10 \mu \mathrm{g} / \mathrm{ml}$ (OXOID) para las cepas bacterianas y fluconazol de $25 \mu \mathrm{g} / \mathrm{ml}$ (OXOID) para la levadura, las placas fueron incubadas a $37{ }^{\circ} \mathrm{C}$ de 18 a 24 horas, transcurrido el tiempo de incubación se midió el halo de inhibición $(4,15)$, y las medidas resultantes fueron comparadas con los valores de sensibilidad sugeridos por la escala de sensibilidad de Duraffourd et al. (16): Sensibilidad nula (-) si fue $\leq 8$ $\mathrm{mm}$, sensible $(+)$ de 9-14 mm, muy sensible $(++)$ de $15-19 \mathrm{~mm}$ y sumamente sensible $(+++) \geq 20 \mathrm{~mm}$.

\section{RESULTADOS}

En base a los resultados la cantidad de muestra liquénica extraída fue de $2,45 \mathrm{~g}$ con un rendimiento de $11,71 \%$; con respecto al análisis químico, el extracto etanólico de Usnea laevis contiene ácido cis-vaccenico $(20,9 \%)$, ácido octadecanóico $(14,7 \%)$, ácido úsnico $(13,3 \%)$ y ácido linoleico $(11,4 \%)$ y otros compuestos que se encontraron presentes en menor proporción (tabla 1). En la tabla 2 se muestran los resultados de la actividad antifúngica y antimicrobiana del extracto frente a las cepas evaluadas, en donde a una concentración de $11 \mathrm{mg} / \mathrm{ml}$ todos los microorganismos probados presentaron resistencia.

\section{DISCUSIÓN}

Pese al desarrollo de antibióticos y medicamentos, la resistencia microbiana y de las enfermedades infecciosas que provocan son una amenaza que va en

Tabla 1. Composición química del extracto etanólico de Usnea laevis por cromatografía de gases acoplado a espectrometría de masas.

\begin{tabular}{llc}
\hline Compuesto & Fórmula & \% \\
\hline Eugenol & $\mathrm{C}_{10} \mathrm{H}_{12} \mathrm{O}_{2}$ & 7,05 \\
6-Pentadecan-1-ol & $\mathrm{C}_{15} \mathrm{H}_{30} \mathrm{O}$ & 2,99 \\
n-Acido hexadecanóico & $\mathrm{C}_{16} \mathrm{H}_{32} \mathrm{O}_{2}$ & 5,70 \\
Ácido hexadecanóico etil ester & $\mathrm{C}_{18} \mathrm{H}_{36} \mathrm{O}_{2}$ & 3,88 \\
Fitol & $\mathrm{C}_{20} \mathrm{H}_{40} \mathrm{O}$ & 1,51 \\
9,12-Acido Octadecanóico & $\mathrm{C}_{18} \mathrm{H}_{32} \mathrm{O}_{2}$ & 14,70 \\
Ácido cis-Vaccenico & $\mathrm{C}_{18} \mathrm{H}_{34} \mathrm{O}_{2}$ & 20,98 \\
Ácido linoléico etil éster & $\mathrm{C}_{20} \mathrm{H}_{36} \mathrm{O}_{2}$ & 11,41 \\
Acido-9-Octadecanoico etil éster & $\mathrm{C}_{20} \mathrm{H}_{38} \mathrm{O}_{2}$ & 9,66 \\
Ácido Octadecanóico etil éster & $\mathrm{C}_{20} \mathrm{H}_{40} \mathrm{O}_{2}$ & 2,19 \\
Ftalato de bis(2-etilhexilo) & $\mathrm{C}_{24} \mathrm{H}_{38} \mathrm{O}_{4}$ & 1,96 \\
Ácido úsnico & $\mathrm{C}_{18} \mathrm{H}_{16} \mathrm{O}_{7}$ & 13,38 \\
Ergosta-5,8,22-trien-3-ol, (3ß,22E) & $\mathrm{C}_{28} \mathrm{H}_{44} \mathrm{O}$ & 1,24 \\
Ergosterol & $\mathrm{C}_{28} \mathrm{H}_{44} \mathrm{O}$ & 3,33 \\
\hline
\end{tabular}


Tabla 2. Actividad antifúngica y antibacteriana del extracto etanólico de Usnea laevis

\begin{tabular}{|c|c|c|c|}
\hline Organismo & $\begin{array}{l}\text { Extracto etanólico de } \\
\text { Usnea laevis }(\mathrm{mg} / \mathrm{ml})\end{array}$ & $\begin{array}{c}\text { Diámetro del Halo de } \\
\text { inhibición }(\mathrm{mm}) X \pm \\
\text { SD }\end{array}$ & $\begin{array}{c}\text { Grado de } \\
\text { Sensibilidad según } \\
\text { Duraffourd }\end{array}$ \\
\hline \multirow{6}{*}{$\begin{array}{l}\text { Candida albicans } \\
\text { ATCC } ® 10231^{\mathrm{TM}}\end{array}$} & 27,5 & $17,07 \pm 0,916$ & Muy sensible \\
\hline & 22,5 & $10,429 \pm 1,398$ & Sensible \\
\hline & 16,5 & ---------- & ------------- \\
\hline & 11 & ----------- & ------------- \\
\hline & Fluconazol (25 ug/ml) & $22,8 \pm 1,082$ & $\begin{array}{l}\text { Sumamente } \\
\text { Sensible }\end{array}$ \\
\hline & Etanol $(96 \%)$ & -------------- & ------------ \\
\hline \multirow{6}{*}{$\begin{array}{l}\text { Pseudomonas aeruginosa } \\
\text { ATCC } \AA 9027^{\mathrm{TM}}\end{array}$} & 27,5 & $14,25 \pm 0,965$ & Sensible \\
\hline & 22,5 & $9,89 \pm 1,278$ & Sensible \\
\hline & 16,5 & 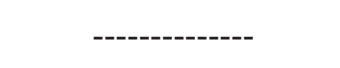 & ------------- \\
\hline & 11 & ------------- & ------------- \\
\hline & Gentamicina $(10 \mathrm{ug} / \mathrm{ml})$ & $18,17 \pm 1,193$ & Muy Sensible \\
\hline & Etanol $(96 \%)$ & -------------- & -------------- \\
\hline \multirow{6}{*}{$\begin{array}{l}\text { Staphylococcus aureus } \\
\text { ATCC }{ }^{\circledR} 25923^{\mathrm{TM}}\end{array}$} & 27,5 & $16 \pm 0,816$ & Muy Sensible \\
\hline & 22,5 & $12,86 \pm 0,864$ & Sensible \\
\hline & 16,5 & $9,50 \pm 1$ & Sensible \\
\hline & 11 & --------- & ----------- \\
\hline & Gentamicina (10 ug/ml) & $20,92 \pm 1,03$ & $\begin{array}{l}\text { Sumamente } \\
\text { Sensible }\end{array}$ \\
\hline & Etanol $(96 \%)$ & --------------- & ------------ \\
\hline
\end{tabular}

(------) Ausencia de halo de inhibición.

aumento y deteriora la efectividad y eficacia de los fármacos haciendo que cada vez se disponga de menos opciones terapéuticas (10), por lo que en la búsqueda de nuevas tratamientos; tanto plantas, hongos y líquenes son importantes para la investigación farmacológica.

En base a los resultados obtenidos de la medición del diámetro del halo de inhibición, con respecto a Candida albicans y Pseudomonas aeruginosa tras exponerlas al extracto etanólico de Usnea laevis indicaron que dos $(27,5 \mathrm{mg} / \mathrm{ml}, 22,5 \mathrm{mg} / \mathrm{ml})$ de estas concentraciones fueron efectivas para estas cepas; en cuanto a Staphylococcus aureus existió halo de inhibición en tres de las cuatro concentraciones probadas, mientras que a una concentración de $11 \mathrm{mg} /$ $\mathrm{ml}$ del extracto no presento actividad antifúngica ni antibacteriana en ninguna de las cepas probadas.

La actividad biológica de los extractos está relacionada directamente con las sustancias liquénicas que lo componen. En base al informe químico obtenido, se identificaron compuestos fenólicos como el eugenol el cual presenta propiedades antisépticas (17) y ha demostrado tener efectos bacteriostáticos $\mathrm{y}$ fungistáticos (18) y bactericidas y fungicidas en altas concentraciones; además su acción es atribuida a que los fenoles tienden a degradar las proteínas, lo que resulta en daño a la membrana celular (19). Se ha señalado que los terpenoides como el Fitol el cual forma parte del extracto, es efectivo frente a hongos, bacterias y protozoos; indicando que presentan propiedades antibacterianas siendo efectivos frente a Bacillis subtili, Escherichia coli, y Staphylococcus aureus (20). Los esteroles como el ergosterol, se han caracterizado por ser los responsables de la actividad antiestafilocócica y antibacteriana producto de la concentración de este tipo de compuestos, incluyendo a los terpenoides (21). Por lo tanto basándonos en 
este contexto la actividad antifúngica y antibacteriana observada podría es atribuida, a la interacción de estos y otros compuestos.

En la literatura no se encontraron trabajos en donde se haya empleado el extracto de Usnea laevis sobre cepas de importancia médica sin embargo en investigaciones previas el ácido úsnico ha resultado ser más efectivo frente a bacterias Gram positivas que bacterias Gram negativas como Staphylococcus epidermidis, $S$. aureus y Enterococcus faecalis (22), corroborando los resultados obtenidos en el presente estudio, donde la actividad antibacteriana del extracto etanólico de Usnea laevis, tuvo mejores resultados con Staphylocuccus aureus, que con Pseudomonas aeruginosa .,sin embargo, en otro estudio utilizando el extracto etanólico de Usnea ghattensis sobre esta misma cepa Gram negativa, se obtuvo un halo de inhibición de 11,3 $\pm 0,5 \mathrm{~mm}$ (5), siendo este un valor ligeramente cercano al obtenido en este estudio, demostrando que los metabolitos secundarios liquénicos presentes en el extracto de Usnea laevis actúan tanto en bacterias Gram positivas como Gram negativas.

También se ha evidenciado su efecto en hongos levaduriformes; según un estudio, en donde se observó inhibición del crecimiento de levaduras patógenas de importancia médica como Candida albicans con resultados significativos (22), por lo tanto en base a lo obtenido el extracto etanólico de Usnea laevis tiene efectos antibacterianos y antifúngicos presentando una buena actividad para ambos casos.

En base a estudios previos se ha determinado también que la toxicidad y el grado de sensibilidad que presentan las cepas frente a un extracto varía de acuerdo a la concentración utilizada obteniendo mejores resultados a concentraciones mayores (23), corroborando así los resultados arrojados en este estudio, en donde se obtuvo mayor halo de inhibición con las concentraciones más altas y con la concentración más baja $(11 \mathrm{mg} / \mathrm{ml})$ el extracto fue inactivo frente a todas las cepas probadas, por lo que se debería trabajar con concentraciones mayores a las probadas en este estudio para obtener mejores resultados tal como lo sugiere otro autor (9).

Es importante mencionar que una de las limitaciones del estudio es que no se realizó la evaluación del efecto bactericida/ bacteriostático y fungicida/fungistático del extracto, sin embargo en base a investigaciones anteriores se conoce que el ácido úsnico, es considerado un potente agente antimicrobiano con acción microbiocida en bacterias Gram positivas (24) y que los compuestos fenólicos como el eugenol ha demostrado tener efectos bacteriostáticos/fungistáticos tanto en bacterias como en hongos (18).

En conclusión el extracto etanólico de Usnea laevis evidencia una gran variedad de metabolitos secundarios tales como el ácido úsnico, eugenol entre otros y posee propiedades antifúngicas y antibacterianas frente a Candida albicans, Pseudomonas aeruginosa y Staphylococcus aureus, excepto a una concentración de $11 \mathrm{mg} / \mathrm{ml}$ la cual es inactiva frente a todas las cepas evaluadas.

\section{Institución donde se realizó:}

Laboratorio de Micología Aplicada de la Universidad Central del Ecuador y Centro de Biología de la Universidad Central del Ecuador.

\section{Correspondencia:}

Cristhina Jaramillo

Hospital del Sur OE 10-321, Código Postal: 170608

Quito, Pichincha, Ecuador

Correo electrónico: cristhina.j14@hotmail.com

Celular: 5930998338696

\section{REFERENCIAS BIBLIOGRÁFICAS}

1. Iliana E. Liquenes usados en Medicina Tradicional. Bol Soc Micol. 2012; 36: 163-174.

2. Müller K. Pharmaceutically relevant metabolites from lichens. Appl Microbiol Biotechnol. 2001; 56(12):9-16.

3. Boustie J, Grube M. Lichens a promising source of bioactive secondary metabolites. Plant Gen Resources. 2005; 3(2):273-287.

4. Viteri R. Estudio fitoquímico del extracto etanólico del liquen Usnea antarctica, procedente de la antártida. Tesis de Maestria. Miranda, Venezuela: Instituto Venezolano de Investigaciones Científicas. 2015; 1-115pp. (Citado el 20 de noviembre del 2018) Disponible en: http://repositorio.educacionsuperior. gob.ec/handle/28000/1784

5. Srivastava P, Upreti K, Dhole N, Srivastava A, Nayak T. Antimicrobial Property of Extracts of Indian Lichen against human pathogenic bacteria. Interdiscip Perspect Infect Dis. 2013; 2013:709348. doi: 10.1155/2013/709348

6. Cavalieri J, Coyle M. Manual de pruebas de susceptibilidad antimicrobiana. Washington DC: 
American Society for Microbiology; 2005. p. 39-65.

7. Gutkind O, Martino G, Graña N, Coussio J, De Torres R. Screening of South American plants for biological activities: Antibacterial and antifungal activity. Fitoterapia. 1981; 52: 213-218.

8. Behera B, Verma N, Sonone A, Makhija U. Antioxidant and antibacterial activities of lichen Usnea ghattensis in vitro. Biotech Letters. 2005; 27(14):991-995.

9. Jaramillo C. Evaluación de la actividad antifúngica del extracto de Usnea laevis en hongos fitopatógenos. Bol Micol. 2018; 33(1): 1-8. DOI: https://doi.org/10.22370/bolmicol.2018.33.1.1091

10. Coates R, Halls G, Hu Y. Novel classes of antibiotics or more of the same? British J Pharm. 2011; 163(1):184-194.

11. Castro O. Aislamiento del ácido úsnico de Flavoparmelia caperata y su determinación cuantitativa por espectroscopia UV, en diez líquenes. Rev Soc Quím Perú. 2010; 76(4):389-399.

12. Castro O. Contribución al estudio fitoquímico del liquen Thamnolia vermicularis. Rev Soc Quím Perú. 2010; 76:19-29

13. Castro O. Aislamiento de ácido úsnico y parietina de Caloplaca saxicola hoffm isolation of the usnic acid and parietin of the Caloplaca saxicola hoffm. Rev Soc Quím Perú. 2011; 77(2):152-161.

14. Adley C. (Ed.). Food-borne pathogens: methods and protocols. Totowa, New Jersey, USA: Springer Science \& Business Media; 2006.

15. Ranković B, Koranic M. Antimicrobial activities of different extracts of Lecanora atra, Lecanora muralis, Parmelia saxatilis, Parmelia sulcata and Parmeliopsis ambigua. Pak J Bot. 2012; 44(1):429-433.

16. Duraffourd C, Lapraz J, Hervicourt L. Cuadernos de fitoterapia clínica. Barcelona: Masson SA; 1987.

17. Fonnegra R, Jiménez S. Plantas medicinales aprobadas en Colombia. Antoquia: Editorial Universidad de Antioquia; 2007. p. 1-7.
18. Colivet J, Belloso G, Hurtado E. Comparación del efecto inhibidor de extractos de ají dulce (Capsicum chinense) sobre el crecimiento de Escherichia coli y Bacillus sp. SABER. 2006; 18(2):168-173.

19. González R. Eugenol: propiedades farmacológicas y toxicológicas. Ventajas y desventajas de su uso. Rev cubana de Estomatol. 2002; 39(2):139-156.

20. Maguna F, Romero M, Garro A, Okulik B. Actividad Antimicrobiana de un grupo de Terpenoides. Rev Comunic Científicas y Tecnol en Int. 2006; 57:4-5.

21. Hervet W, González L, Payo L. Metabolitos secundarios y actividad antimicrobiana de Pluchea carolinensis. Rev Cubana de Farm. 2006; 40(2):1020.

22. Francolini I, Taresco V, Crisante F, Martinelli C, D’Ilario L, Piozzi A. Water soluble usnic acidpolyacrylamide complexes with enhanced antimicrobial activity against Staphylococcus epidermidis. Int J Mol Sci. 2013; 14(4):7356-7369. doi: 10.3390/ijms14047356

23. Vaillant-Flores D, Gómez-Peralta M, Romeu-Carballo C, Ramírez-Ochoa R, Porras-González A. Actividad antifúngica de extractos de tres especies de líquenes en Cuba. Agron Mesoamericana. 2015; 26(2):345350 .

24. Melgarejo M, Sterner O, Vila J, Mollinedo P. More Investigations in Potent activity and Relationship Structure of the Lichen Antibiotic (+)- Usnic Acid and its Derivate Dibenzoyl usnic Acid. Rev Bol Quím. 2008; 25(1):24-29.

Recibido: 19/06/2019

Aceptado: 25/06/2020 